
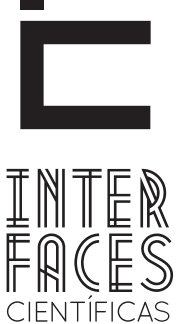

DIREITO

\title{
HABEAS CORPUS, RECURSO ORDINÁRIO EM HABEAS CORPUS E A (DESICONSTRUÇ̃̃O JURISPRUDENCIAL PENAL
}

\section{RESUMO}

Este estudo objetivou criticar a nova mudança jurisprudencial pelo Supremo Tribunal Federal e pelo Superior Tribunal de Justiça, por não mais admitirem o Habeas Corpus, substitutivo de Recurso Ordinário em Habeas Corpus, inclusive em função dos precários motivos apresentados, de exacerbado volume de impetrações de habeas corpus, de que com isso estariam sendo desmoralizadas as instâncias ordinárias e de que o habeas substitutivo é inadequado ante a sua falta de previsão no texto constitucional, são esses os argumentos utilizados pelos tribunais superiores para justificarem a mudança de entendimento na sua jurisprudência. Ocorre que, logicamente, isso não resolve em nada o "problema", apenas o agrava, haja vista que se o advogado perder o prazo de interposição do recurso ordinário, quem sai prejudicado é o jurisdi- cionado (paciente), com sua liberdade mitigada, em função do transito em julgado da decisão que denegou a ordem nada mais caberá, ficando sujeito a uma decisão (do órgão jurisdicional “a quo") ilegal que não mais poderá ser analisada. Depois de vários anos de jurisprudência consolidada resolvem agora modificar. Serão interpostos recursos ordinários de habeas corpus, quase que na mesma quantidade de habeas corpus substitutivos, não diminuindo o número de casos nas cortes superiores.

\section{PALAVRAS-CHAVE}

Recurso Ordinário. Habeas Corpus. Jurisprudência. Liberdade. Direitos e Garantias Fundamentais. 


\section{ABSTRACT}

This study aimed to criticize the new change of jurisprudence by the Supreme Court and the Superior Court of Justice for no more admit the Habeas Corpus replacement of Ordinary Appeal in Habeas Corpus, even in light of the precarious reasons presented in exaggerated volume requests for habeas corpus, that it would be demoralized the ordinary instances and that the habeas substitute is inappropriate before his lack of foresight in the constitutional text, these are the arguments used by superior courts to justify a change of understanding in its jurisprudence. It happens that, logically, it does not solve anything in the "problem", only worse, considering that if the lawyer miss the deadline for filing an ordinary appeal, who is harmed is the patient, with their freedom mitigated in function of transit in the trial decision dismissing the order nothing else will fit, subject to a decision (the court "a quo") illegal can no longer be analyzed. After several years of consolidated jurisprudence resolve now modify. Resources will be brought ordinary habeas corpus, almost the same amount of habeas corpus substitute, not decreasing the number of cases in the superior courts.

\section{KEYWORDS}

Ordinary Appeal. Habeas Corpus. Jurisprudence. Freedom. Fundamental Rights and Guarantees.

\section{INTRODUÇ̄̃O}

Na República Federativa do Brasil foi instituído o modelo do Estado Democrático de Direito, que possui como missão precípua a de promover os direitos e garantias fundamentais aos seus cidadãos.

\section{RESUMEN}

Este estudio tuvo como objetivo criticar el nuevo cambio de la jurisprudencia del Supremo Tribunal Federal y del Superior Tribunal de Justicia por no más admitir que el Habeas Corpus sea substituto de Recurso Ordinario em Habeas Corpus, incluso a la luz de las precarias razones que se presentan de volúmenes exagerados de habeas corpus, de con eso serian desmoralizadas las instancias ordinarias y de que el habeas sustituto no es apropiado delante de su falta de previsión en el texto constitucional, estos son los argumentos utilizados por los tribunales superiores para justificar un cambio de entendimiento en su jurisprudencia. Sucede que, lógicamente, esto no resuelve nada del "problema", sólo lo empeora, teniendo en cuenta que si el abogado no cumple con el plazo para la presentación de un procedimiento de apelación, el perjudicado será el jurisdicionado (paciente), con su libertad mitigada en función de la cosa juzgada de la decisión que denegó el juicio no habrá nada más que hacer, estando sometido a una decisión (del tribunal "a quo") ilegal que ya no puede ser analizado. Después de varios años de jurisprudencia afirmada ahora resuelven modificar. Serán interpuestos recursos ordinarios de habeas corpus, casi en la misma cantidad de habeas corpus sustitutos, sin disminuir el número de casos en los tribunales superiores.

\section{PALABRAS CLAVE}

Recurso Ordinario. Habeas Corpus. Jurisprudencia. Libertad. Derechos y Garantías Fundamentales

Neste sentido, no atual sistema jurídico brasileiro, o processo penal apenas pode ser legitimado na qualidade de instrumento garantidor dos direitos e garantias individuais, vez que é o único caminho para a pena, ou seja, é imprescindível que a pena apenas 
seja estabelecida por meio do devido processo legal.

Com efeito, surge daí a real importância da ação de habeas corpus, como instrumento processual apto a defender a liberdade de ir e vir do paciente contra os atos abusivos do Estado, assegurando que no processo penal em que o paciente esta sendo acusado (jurisdicionado) venha a ser respeitada as regras processuais estabelecidas em lei.

Todavia, o writ $^{1}$ está sendo hostilizado pelo novo entendimento jurisprudencial das cortes superiores, que por sua vez não estão mais aceitando o habeas corpus substitutivo do recurso ordinário em habeas corpus, sob o pretexto de excesso de impetrações, de que dessa forma estariam sendo desmoralizadas as instâncias ordinárias e de que é inadequado ante a falta de previsão no texto constitucional.

\section{PROBLEMATIZANDO A DISCUSSÃO}

A princípio, faz-se necessário apresentar os motivos que ensejaram a recente discussão do não cabimento do habeas corpus, como substitutivo do recurso ordinário constitucional de habeas corpus, para depois disso construirmos a solução que entendemos mais adequada.

Assim, em crítica veiculada no sítio eletrônico do Superior Tribunal de Justiça, o Ministro Gilson Dipp, manifesta seu repúdio, vez que ante o grande número de impetrações de habeas corpus, tendo o instrumento utilizado de modo indiscriminado em substituição ao recurso próprio, gerando a desmoralização do sistema ordinário, e, que deve ser protegido certos limites para que o habeas corpus seja respeitado na sua credibilidade e funcionalidade ${ }^{2}$.

\section{A expressão inglesa significa um mandamento judicial.}

2 DIPP, Gilson. Critica utilização excessiva de habeas corpus. Sítio eletrônico do STJ, seção de notícias. Disponível em: <www.stj.jus.br>. Acesso em: 16 jan. 2013.
Em verdade, esses argumentos não devem ser aceitos como válidos para modificar a jurisprudência consolidada do habeas corpus, utilizado como sucedâneo recursal em substituição ao recurso ordinário em habeas corpus.

No Direito deveria prevalecer o entendimento de que não importaria o instrumento utilizado para realizar o pedido, mas sua procedência ou não, e o excesso de formalidades não devem prevalecer em detrimento aos direitos e garantias fundamentais do cidadão (jurisdicionado).

O principio da instrumentalidade das formas pode ser compatibilizado com a ação de habeas corpus, dessa união pode ser encontrada uma solução.

Dipp conclui sua crítica, abalizando que a utilização legítima do habeas corpus substituindo os recursos cabíveis tem sido cada vez mais aceito nos tribunais superiores, e que não pretende desmerecer a jurisprudência, mas que deve haver limites para que não seja perdida a razão lógica e sistemática dos recursos em função de uma irrefletida banalização do habeas corpus.

As críticas não param por aí, nesse sentido importante precedente é o Habeas Corpus 109.956/PR, julgado pela $1^{\text {a }}$ Turma do Supremo Tribunal Federal, em que alega o Ministro Relator Marco Aurélio sobre a inadequação do habeas corpus quando o caso sugere recurso ordinário constitucional.

No seu voto, continua o Relator no sentido de que tendo em vista a sobrecarga de processos, bem como a falta de previsão para o cabimento na lei fundamental, não mais deveria então ser admitido o habeas 
substitutivo do recurso ordinário constitucional, previsto contra decisão judicial a implicar o indeferimento da ordem.

Ato contínuo, o Ministro Marco Aurélio argumenta que não haverá prejuízo ao paciente no tocante a habeas corpus já formalizado sob a óptica da substituição do recurso constitucional, já que seria possível conceder a ordem de ofício.

Por fim, Marco Aurélio critica severamente a comodidade da utilização do habeas corpus substitutivo ante a falta de prazo para a sua impetração, vez que na interposição do recurso tal não ocorre. Defende que isso muitas vezes ocorre como pretexto para que a passagem do tempo venha a desaguar, por vezes, na prescrição. Votando pela inadequação do habeas substitutivo.

Ainda no Habeas Corpus 109.956/PR, a Ministra Rosa Weber acompanha o entendimento do Ministro Relator, assim como o faz a Ministra Carmen Lúcia, que por sua vez defende ser inadequada a via do habeas corpus utilizado para substituir recursos legalmente previstos no sistema processual.

Ao final do seu voto, a Ministra Carmen Lucia repreende a utilização do habeas substitutivo, vez que como consequência do seu manejo ocorre uma série de alterações, como a alteração de competências, alteração de requisitos, o que enseja no enfraquecimento do próprio instituto do habeas corpus. Votando pela não concessão da ordem, ante a sua inadequação.

No entanto, ainda no Habeas Corpus 109.956/PR, ao fim do seu julgamento pela $1^{\text {a }}$ Turma do Supremo Tribunal Federal, o então Presidente da $1^{\mathrm{a}}$ Turma, Ministro Dias Toffoli, discorda dos seus pares por não verificar motivos que justifiquem embaraçar a viabilização do acesso do habeas corpus como substitutivo do recurso ordinário.

Dias Toffoli argumenta que desde o Código Processual Penal do Império, é previsto que, sempre que um juiz, ou tribunal, se depare com uma ilegalidade, ele deve conceder a ordem, mesmo que de ofício, se for o caso de constrição à liberdade de ir e vir do cidadão, e por fim, registra o seu voto vencido.

Desde então, os tribunais superiores vem cada vez mais resistindo, no sentido de não mais viabilizarem o habeas corpus como substitutivo ao recurso próprio, entendimento jurisprudencial que só vem a prejudicar o jurisdicionado, sem fundamento lógico para tanto conforme se verá no desenvolver do presente trabalho.

\section{PONTOS DE PARTIDA PARA A EFETIVAÇÃO DO "HABEAS CORPUS" COMO GARANTIA AO DIREITO DE LIBERDADE}

Inicialmente, se faz necessário defender o modelo de Estado Democrático de Direito, centrado como ponto de partida para alcançarmos a defesa dos direitos e garantias individuais explícitos e implícitos da Constituição da República Federativa do Brasil de 1988.
Com o objetivo de assentar o modelo de Estado Democrático de Direito no Brasil, buscou-se instituir para a nossa República, princípios e garantias fundamentais a serem buscados durante toda atividade estatal, sob pena de ruir toda estrutura do texto constitucional, não sendo inclu- 
sive permitido transigir com direitos e garantias individuais.

Dentre estes direitos e garantias fundamentais, assegurados pela Constituição, principalmente os declarados no seu artigo $5^{\circ}$. Destaca-se pela sua grandeza própria o inciso LXVIII, o qual institui a garantia processual do habeas corpus, quando "alguém sofrer ou se achar ameaçado de sofrer violência ou coação em sua liberdade de locomoção por ilegalidade ou abuso de direito".

Como instrumento de garantia da liberdade de locomoção, o habeas corpus se comporta essencialmente como ação penal, atrelada à necessidade de prova pré-constituída, cuja utilização durante toda a persecução criminal, tanto na fase investigativa do inquérito policial tanto quanto na fase judicial do processo penal, onde a conclusão possa vir a tornar-se pena privativa de liberdade, com exceção do caso de transgressão disciplinar militar.

Empregado sempre nas hipóteses de violação ou ameaça de violação à liberdade de ir e vir do indivíduo (causa de pedir do "writ"), o habeas corpus como garantia fundamental que é, deve ser compreendido de maneira ampla, podendo sua impetração se dar preventivamente (salvo-conduto), repressivamente (liberatório), suspensivamente (existindo constrangimento ilegal, mas sujeito ainda não foi preso), e profilaticamente (impugnação de medidas que futuramente possam gerar prisão com aparência de legalidade, mas cominada por ilegalidade anterior). (TÁVORA e ALENCAR, 2012)

Para Alberto Zacharias Toron (2001, n.p.), o habeas corpus:

[...] além de tutelar de forma imediata a liberdade de ir e vir, tem permitido, com iniqualável eficácia, assegurar o devido processo legal e, por via mediata, a mesma liberdade e a própria dignidade do cidadão atingido por um processo viciado.
Desta feita, o Direito Penal não possui coerção direta, logo para que possa ser aplicada uma pena, se faz necessário não apenas o cometimento do crime pelo agente, como também que seja assegurado o devido processo legal (LOPES JR., 2005).

Isto se justifica em razão de que a pena não apenas é um efeito do injusto penal praticado, como também é um efeito do processo, todavia o processo não é efeito do delito, senão da necessidade de impor a pena ao delito por meio do processo (LOPES JR., 2012)

A consequência logica então é que o delito, o processo e a pena estão interligados, de modo que se o processo termina antes do seu desenvolvimento completo, ou caso esse não se desenvolva de forma válida, não poderá ser imposta a pena.

Neste contexto, o habeas corpus se insere como remédio heroico, assegurando o jurisdicionado para que não venha a sofrer restrição da sua liberdade (pela pena) indevidamente em função de alguma irregularidade advinda no processo, isto se dá em função da leitura constitucional do processo penal.

Pois, se antes a grande discussão era entre o direito positivo e o direito natural, hoje como os direitos naturais estão recepcionados pelas modernas constituições democráticas, o desafio é outro, qual seja: o de dar eficácia a esses direitos fundamentais (LOPES JR., 2012).

Desta feita, devemos ter consciência de que a Constituição deve efetivamente constituir (entendendo-se isso por consciência de que ela constitui-a-ação), para que se compreenda o fundamento legitimante do processo penal como instrumento a serviço do projeto democrático, por via de consequência, garantidor da eficácia dos direitos e garantias fundamentais (LOPES JR., 2012). 


\section{HABEAS CORPUS SUBSTITUTIVO DE RECURSO ORDINÁRIO EM HABEAS CORPUS VERSUS TRI- BUNAIS SUPERIORES}

Pedro Machado de Almeida Castro faz interessante abordagem histórica, no sentido de que com o Ato Institucional 6, logo após com a Emenda Constitucional 1 da Constituição de 1968, ficou proibido expressamente a substituição do recurso ordinário em habeas corpus pelo pedido originário de habeas corpus (CASTRO, 2012).

Em que pese naquela época ainda não existir o Superior Tribunal de Justiça, problema resolvido com a promulgação da Constituição de 1988, onde também foi retirada a proibição da Constituição antecedente, voltando a ser aceito pelo Supremo Tribunal Federal o habeas corpus substitutivo do recurso ordinário em habeas corpus (CASTRO, 2012).

Interessante julgado é o Habeas Corpus 78.897/ RJ, em que o Ministro Maurício Corrêa por meio do seu voto (inclusive sendo acompanhado pelos seus pares, com exceção do Relator) assevera que havendo coação ilegal sobre a liberdade de locomoção em qualquer lugar, em processo de qualquer espécie e seja quem for a autoridade coatora, caberá habeas corpus perante o Supremo Tribunal Federal, conforme possibilita a emenda constitucional 22.

Todavia, em que pese o entendimento jurisprudencial daquela época precisamos rever os limites do habeas corpus na atualidade, sob pena de perdê-lo, não defendemos aqui a idaia de que o habeas corpus caberá sempre e em todas as hipóteses, mas também não é pelo extremo oposto que será atingido uma solução adequada ao problema posto.

Não devemos, ainda, nos esquecer do objetivo central, qual seja, a garantia da liberdade humana injusta ou ilegalmente restringida.
No tocante a afirmação do Ministro Gilson Dipp, interessante manifestação de Alberto Zacharias Toron, no sentido de que a desmoralização das instâncias ordinárias por acaso estaria atrelada com a mesma grita autoritária de alguns "superjuízes" das Varas Federais especializadas, contra as ordens de habeas corpus que o STF concedeu ora para determinar, por exemplo, que se desse vista dos autos de inquérito policial à defesa, ora para declarar a ilegalidade de provas obtidas em desrespeito ao devido processo legal? (TORON, 2011)

Continua Toron, defendendo que também deve se perguntar, o que há de desmoralizante para as instâncias ordinárias quando, por exemplo, se concede habeas corpus para trancar uma ação penal carente de justa causa? Deveriam nesses casos o erro e a injustiça subsistir para preservar-se o bom nome dessas instâncias? (TORON, 2011)

De fato, temos uma linha bastante tênue no que tange a esse limite do que cabe e do que não cabe, simplificando, a resposta se resume no que o Magistrado que for apreciar o habeas corpus entender, assim como é delicado o limite do que seria e do que não seria desmoralizar as instâncias ordinárias, não sendo o erro e a injustiça, justificativas para tanto.

Ademais, a jurisprudência brasileira sedimentou-se no entendimento de que a recorribilidade da decisão ou a efetiva pendência de recurso contra eles não inibe a admissibilidade paralela do habeas corpus, inclusive no que tange a pendencia de julgamento de recurso de apelação (TORON, 2011).

Alguns julgados indicam a possibilidade de impetração de habeas corpus, mesmo com a pendência de 
recurso a ser apreciado pelo Tribunal, como por exemplo, no Recurso Ordinário em Habeas Corpus 82.045 do STF, no Habeas Corpus 77.703/SP do STJ, no Habeas Corpus 78.897/RJ do STF e no Habeas Corpus 77.858/AM do STF.

Desta forma, se cabe habeas corpus na pendência, por que não em substituição ao próprio recurso? Valendo para a apelação, valerá ainda mais para o habeas corpus em simultaneidade com o recurso especial ou ordinário.

Isto se dá, em razão de que ambos têm o mesmo campo cognitivo, logo na impetração do habeas subs- titutivo tudo se abreviará em ver sanado o constrangimento ilegal sofrido pelo paciente, seja decorrente da falta de justa causa (CPP, art. 648, I), ou, seja decorrente de nulidade (inc. VI) (TORON, 2011).

Em que pese estar sendo defendido o cabimento do habeas corpus substitutivo do recurso especial em habeas corpus, de igual modo, pode-se defender a impetração do habeas corpus substitutivo do recurso ordinário em habeas corpus, são situações diferentes, mas bem parecidas, que objetivam ambas combater a decisão denegatória da ordem de habeas corpus.

exageros dos agentes estatais incumbidos da repressão penal.

Destarte, deveria prevalecer o entendimento de que não importaria o instrumento utilizado para realizar o pedido, mas sua procedência ou não, isto se põe com base também no principio da instrumentalidade das formas.

Neste tocante, no mínimo intrigante é o voto do Ministro Marco Aurélio no Habeas Corpus 86.864/SP, onde defende enfaticamente o remédio heroico como ação constitucional de envergadura maior decorrente do direito natural que é a liberdade.

Além disso, a ação de habeas corpus, possui uma causa de pedir próxima (os fundamentos jurídicos da liberdade de locomoção do paciente), e possui uma causa de pedir remota (elementos fáticos que detalham o ato que violou ou ameaçou a liberdade de locomoção do paciente), de modo que ambas irão delinear os limites da coisa julgada do habeas corpus. 
Sendo assim, não havendo a identidade de causas de pedir próxima e remota caberá a renovação do habeas corpus na mesma instância, pois os efeitos da coisa julgada não poderiam obstaculizar a nova impetração.

Do mesmo modo, havendo identidade entre as ações de habeas corpus, tendo o prazo do recurso cabível se esvaído, nada mais adequado do que utilizar o habeas corpus como sucedâneo recursal via impetração de habeas substitutivo no órgão ad quem.

Devemos defender os direitos e garantias fundamentais, sendo o habeas corpus apenas uma das garantias adquiridas, através de uma série de conquistas obtidas aos poucos e com muita dificuldade pelo povo brasileiro. A República deve progredir ainda mais para alcançar o que se exige na Constituição Federal de 1988.

A liberdade de locomoção, direito básico para que o cidadão alcance a sua dignidade, deve ser defendida até mesmo nos casos em que haja potencialidade de que o seu constrangimento ilegal venha a ocorrer, quando então poderá ser impetrado o habeas corpus profilático.

Frise-se que, a ação de habeas corpus, e é nisso que se deve focar, é de fundamental importância para o desenvolvimento do Estado Democrático de Direito, visto que é destinado a restringir os atos abusivos do Estado.

É de suma importância a existência de instrumentos processuais como o habeas corpus (por isso garantia), que objetivam efetivar os direitos e garantias individuais do cidadão submetido ao poder estatal.

Não devemos retroceder e simplesmente aceitar essa mudança jurisprudencial das cortes superiores de não mais aceitarem o habeas corpus substitutivo do recurso ordinário (ou até mesmo no caso do recurso especial) de habeas corpus.

Esse excesso de formalismo em nada contribui, e apenas objetiva cercear o alcance e a eficácia do habeas corpus, e consequentemente inviabilizar a defesa do jurisdicionado (paciente), mais fraco na relação processual penal.

\section{REFERÊNCIAS}

BRASIL. Constituição da República Federativa do Brasil de 1988. Brasília: Senado Federal. Disponível em: <http://www.planalto.gov.br/ccivil_03/constituicao/ constitui\%C3\% A7ao.htm>. Acesso em: 10 jan. 2013.

BRASIL. Decreto-Lei n 3.689, de 3 de outubro de 1941. Código de Processo Penal. Brasília: Senado Federal. Disponível em: <http://www.planalto.gov.br/ccivil_03/decreto-lei/del3689.htm>. Acesso em: 16 jan. 2013.

CASTRO, Pedro Machado de Almeida. $H C$, RHC e o retrocesso no Processo Penal brasileiro. Boletim $\mathbf{n}^{\circ} \mathbf{2 4 1}$ do IBCCRIM. Dezembro/2012.

DIPP, Gilson. critica utilização excessiva de habeas corpus. Disponível em: <http://www.stj.jus.br/portal_stj/ publicacao/engine.wsp?tmp.area=398\&tmp.texto=100851>. Acesso em: 16 jan. 2013 . 
LOPES JR., Aury. Direito Processual Penal e a sua Conformidade Constitucional. 9. ed. São Paulo: Editora Saraiva, 2012.

LOPES JR., Aury. A Instrumentalidade no processo penal. Disponível em: <http://www.juspodivm.com.br/jp/i/ f/\%7B34561569-847D-4B51-A3BD-B1379C4CD2C6\%7D_022.pdf>. Acesso em: 17 dez. 2012.

TORON, Alberto Zacharias. O habeas corpus pede socorro. Boletim nº 226 do IBCCRIM. Setembro/2011. Disponível em: <http://www.ibccrim.org.br/novo/boletim_artigo/4435-0-habeas-corpus-pede-socorro->. Acesso em: 16 jan. 2013.

TÁVORA, Nestor e ALENCAR, Rosmar Rodrigues. Curso de Direito Processual Penal. 7. ed. Salvador: Juspodivm, 2012. 